\title{
ANALISIS STRATEGI JOINT VENTURE PT. XYZ DENGAN JKL CO., LTD MENGGUNAKAN METODE REVENUE SHARING
}

\author{
Intar Abimantrana ${ }^{1}$, Hetty Karunia Tunjungsari ${ }^{2}$ \\ ${ }^{1}$ Program Studi Magister Manajemen, Universitas Tarumanagara \\ Email : intar_a@yahoo.com \\ ${ }^{2}$ Magister Manajemen, Universitas Tarumanagara \\ Email:hettyt@fe.untar.ac.id
}

Masuk : 30-03-2019, revisi: 10-04-2019, diterima untuk diterbitkan : 30-04-2019

\begin{abstract}
ABSTRAK
Pengembangan pasar pada dunia penerbangan menjadi tantangan tersendiri bagi maskapai penerbangan salah satunya maskapai penerbangan PT. XYZ. Salah satu kajian strategi yang penulis teliti mengenai analisis joint venture antara PT. XYZ dan JKL Co., Ltd dengan menggunakan metode revenue sharing. Penelitian ini bertujuan memberikan analisis joint venture guna mengembangkan pasar sektor Jepang baik dari sisi market share maupun route profitability. Dengan menggunakan formula S. Curve dapat diidentifikasi potensi kenaikan market share bagi kedua maskapai penerbangan dan selanjutnya dapat dihitung route profitability dengan mempertimbangkan capacity share dan ratarata tarif baru. Market share bagi kedua maskapai pada rute DPS-NRT-DPS meningkat 16,56\%, dan pada rute CGKKIX-CGK meningkat 66,51\%, sementara pada rute DPS-KIX-DPS market share meningkat 23,08\%, disisi lain market share pada rute CGK-HND-CGK menurun 7,83\%. Hasil route profitability untuk 4 tahun mendatang yang menunjukkan peningkatan yang cukup signifikan setelah penyesuaian terhadap nilai rata-rata tarif yang baru dan capacity share. Dengan demikian strategi joint venture antara PT. XYZ dan JKL Co., Ltd dapat direkomendasikan untuk penjajakan lebih lanjut.
\end{abstract}

Kata kunci: joint venture, analisis, market share, route profitability

\section{ABSTRACT}

Market development in the aviation world is a challenge for airlines, one of which is PT. XYZ One study of the strategies that the author carefully regarding the analysis of a joint venture between PT. XYZ and JKL Co., Ltd using revenue sharing methods. This study aims to provide a joint venture analysis to develop the Japanese sector market both in terms of market share and route profitability. By using the S. Curve formula, it can be identified the potential increase in market share for the two airlines and then route profitability can be calculated by considering the capacity share and the new average rate. Market share for the two airlines on the DPS-NRT-DPS route increased by $16.56 \%$, and on the CGK-KIX-CGK route increased by $66.51 \%$, while on the DPS-KIX-DPS route the market share increased by $23.08 \%$, on the other hand market share on the CGK-HND-CGK route decreased by $7.83 \%$. The route profitability results for the next 4 years show a significant increase after adjusting the new average rate and capacity share. Thus the joint venture strategy between PT. XYZ and JKL Co., Ltd can be recommended for further exploration.

Keywords: joint venture, analysis, market share, route profitability

\section{PENDAHULUAN}

\section{Latar Belakang}

Indonesia sebagai Negara kepulauan yang letaknya strategis di kawasan Asia Tenggara menjadikan destinasi bagi para wisatawan dari berbagai mancanegara. Berdasarkan data Kementrian Pariwisata (Kemenpar) periode Januari-Desember tahun 2017 tercatat jumlah wisatawan mancanegara (wisman) yang datang sebanyak 14.039.000 orang dimana meningkat sebesar $21,88 \%$ dari periode yang sama pada tahun sebelumnya yang berjumlah 11.519.275 orang. Jumlah wisatawan dari Jepang periode Januari-Desember 2017 tercatat sebanyak 538.334 orang dimana jumlah ini meningkat $4,88 \%$ dibanding periode yang sama tahun sebelumnya.

PT. XYZ (XX) sebagai national flag carrier memiliki peran penting dalam industri transportasi udara khususnya di wilayah Asia Pasifik. Dengan adanya 22 rute internasional per Mei 2018 yang dilayani oleh PT. XYZ serta tergabung dalam aliansi SkyTeam maka jaringan rute internasional semakin luas dan memberikan kemudahan kepada pelanggan dalam melakukan perjalanan. Untuk 
rute Jepang, hingga tahun ini PT. XYZ melayani rute Cengkareng (CGK) - Haneda (HND) pp, Cengkareng (CGK) - Osaka (KIX) pp, Denpasar (DPS) - Osaka (KIX) pp, dan Denpasar (DPS) - Narita (NRT) pp dengan frekuensi satu kali penerbangan per hari.

JKL menjalin kerjasama dengan beberapa maskapai penerbangan internasional diantaranya Joint Venture dengan American Airline pada Oktober 2010. Pada tahun 2010 JKL mulai menunjukkan kinerja yang baik dengan pertumbuhan penumpang 1,1\% Year -on-Year (YoY). Menurut ICF SH\&E (2014), joint venture antara JKL dan American Airline telah berhasil meningkatkan market share sebesar $14 \%$. Saat ini strategi joint venture tersebut akan dijajaki kembali dalam memperkuat pasar di Indonesia salah satunya dengan maskapai PT. XYZ.

PT. XYZ pada rute DPS-KIX-DPS memiliki proporsi sebesar 77,35\% dan mendominasi pasar di rute Jepang tersebut. Secara market share dari rute-rute sektor Jepang, PT. XYZ memiliki market share yang cukup signifikan untuk menangkap traffic di wilayah Jepang. Sisi lain JKL walaupun hanya memiliki rute CGK-NRT-CGK namun proporsinya sebesar 56,29\% dan mendominasi pasar di rute tersebut.

\section{Rumusan Masalah}

Dengan melihat posisi market share PT. XYZ dan JKL yang kuat pada sektor rute Indonesia dan Jepang maka pada penelitian ini rumusan masalah yang akan dikaji sebagai berikut:

1. Bagaimana analisis kerjasama joint venture antara PT. XYZ dengan JKL untuk peningkatan market share?

2. Bagaimana analisis kerjasama joint venture antara PT. XYZ dengan JKL untuk peningkatan profitability?

\section{Tujuan Penelitian}

Berdasarkan rumusan masalah tersebut maka penelitian ini bertujuan untuk mengkaji analisis joint venture antara PT. XYZ dengan JKL baik dari sisi market share maupun route profitability.

\section{Ruang Lingkup Penelitian}

Ruang Lingkup Penelitian ini adalah menganalisis joint venture PT. XYZ dengan JKL baik dari sisi market share maupun profitability. Penelitian analisis joint venture ini dilakukan di PT. XYZ dengan melibatkan unit-unit terkait seperti Corporate Planning and Program Office, Alliance and Partnership Management, dan Revenue Management.

\section{Manfaat Penelitian}

Penelitian ini diharapkan dapat memberikan manfaat sebagai berikut:

1. Memperkaya studi dalam bidang bisnis penerbangan dan sebagai bahan rujukan serta informasi dalam penelitian selanjutnya.

2. Memberikan informasi kepada PT. XYZ sebagai pertimbangan dalam pengambilan keputusan strategi joint venture untuk keberlangsungan bisnis secara jangka panjang khususnya di rute Jepang.

\section{METODE PENELITIAN}

\section{Jenis Metode Penelitian}

Pada metode penelitian ini yang penulis lakukan yakni terkait penelitian deskriptif dimana metode yang digunakan untuk mencari unsur-unsur, ciri-ciri, sifat-sifat suatu fenomena. Metode ini dimulai dengan mengumpulkan data, menganalisis data, dan menginterpretasikannya (Suryana, 
2010). Pendekatan metode penelitian yang dilakukan dengan menggunakan metode kualitatif dan kuantitatif (campuran).

Peneliti mengumpulkan data yang bersifat kualitatif yakni dengan cara melakukan studi pustaka/pengamatan dan wawancara. Sedangkan data yang bersifat kuantitatif penulis dapatkan dari data internal perusahaan PT. XYZ serta menganalisisnya untuk menentukan kelayakan joint venture dengan JKL baik dari sisi market share maupun profitability.

\section{Sumber Data}

Data yang diperoleh dalam penelitian ini yakni bersumber dari data primer dan data sekunder. Data primer diperoleh dari beberapa wawancara dengan unit terkait di PT. XYZ khususnya berkenaan dengan Corporate Planning and Program Office, Alliance and Partnership Management, dan Network Insight. Untuk data sekunder diperoleh dari data internal perusahaan PT. XYZ seperti:

1. Data traffic penerbangan non-stop dan stop-over PT. XYZ khususnya rute DPS-NRTDPS, CGK-KIX-CGK, DPS-KIX-DPS, dan CGK-HND-CGK selama periode Januari sampai Desember tahun 2017.

2. Data route profitability penerbangan non-stop dan stop-over PT. XYZ khususnya rute DPS-NRT-DPS, CGK-KIX-CGK，DPS-KIX-DPS, dan CGK-HND-CGK selama periode Januari sampai Desember tahun 2017.

Selain data internal perusahaan PT. XYZ, data sekunder juga diperoleh dari studi literatur berupa jurnal-jurnal penelitian ataupun artikel yang berkaitan dengan joint venture pada maskapai penerbangan di dunia.

\section{Metode Analisis}

Penulis melakukan metode dalam analisis pada penelitian ini dengan alur diagram sebagai berikut:

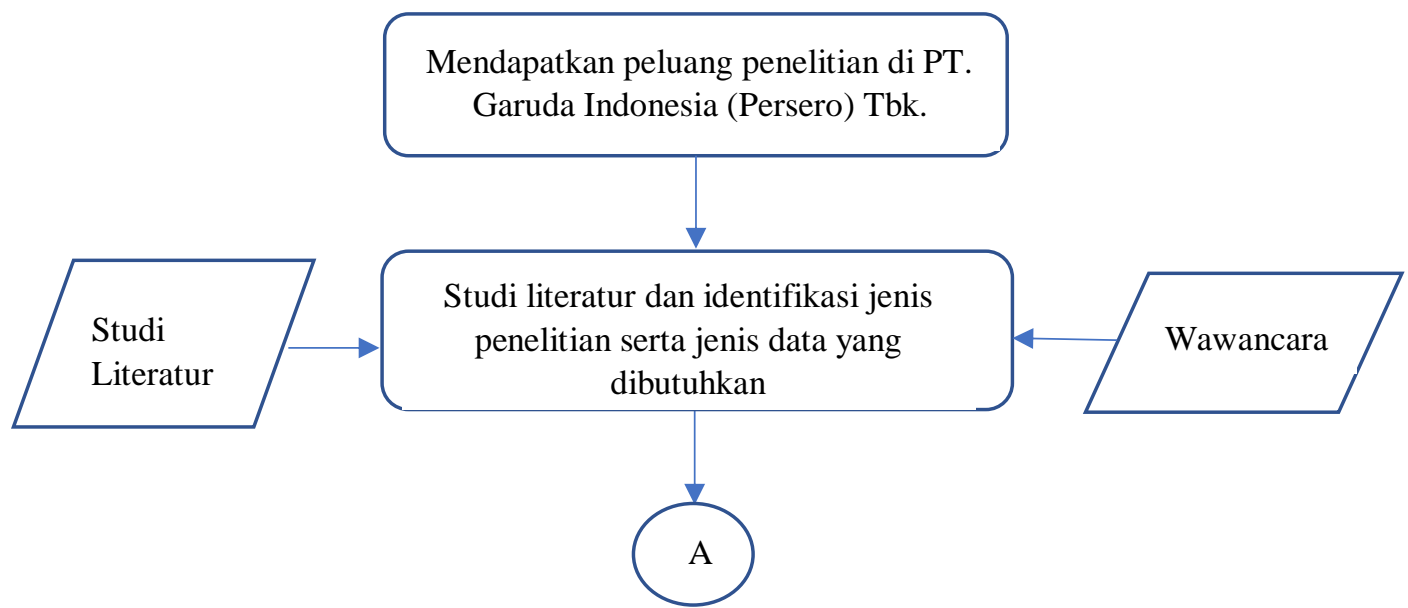




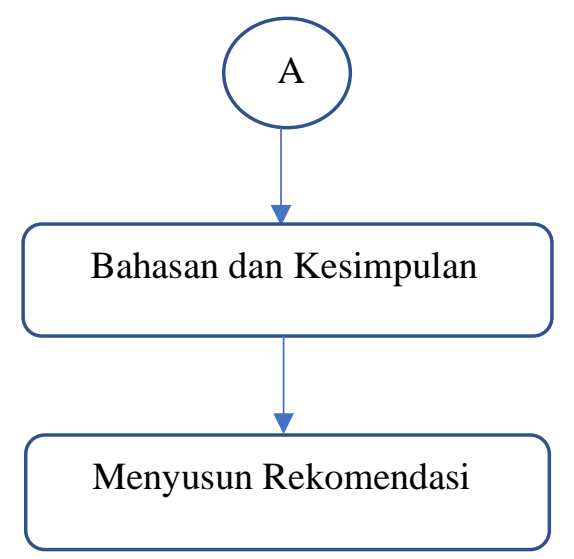

\section{HASIL DAN PEMBAHASAN}

\section{Market Share}

Dengan menggunakan formulasi S-Curve oleh S. Belobaba yang dijabarkan pada Persamaan 1 dan data traffic yang diperoleh dari PT. XYZ untuk tahun 2017 maka untuk rute-rute Jepang yang dilayani PT. XYZ diperoleh peningkatan market share yang dipaparkan dalam Tabel 1.

$$
\mathrm{MS}(\mathrm{XX}+\mathrm{JK})=\frac{F S(X X+J K)^{\alpha}}{F S(X X+J K)^{\alpha}+F S(O T H E R S)^{\alpha}}
$$

Dimana :

MS (i) $=$ Market Share maskapai penerbangan i

FS (i) = Frequency Share non-stop flight dari maskapai penerbangan i

$a=$ Nilai Exponen, nilai untuk penerbangan non-stop berkisar antara 1,3 (long-

haul) dan 1,7 (short-haul). Untuk $a=1$ maka FS (i) = MS (i).

Tabel 1. Proporsi Peningkatan Market dan Frequency Share XX Pada Sektor Rute Jepang

Setelah Joint Venture

\begin{tabular}{ccc}
\hline Rute & Frequency Non-Stop & Traffic Non-Stop XX+JK \\
\hline DPS-NRT-DPS & $1,03 \%$ & $16,56 \%$ \\
\hline CGK-KIX-CGK & Tetap & $66,51 \%$ \\
\hline DPS-KIX-DPS & Tetap & $23,08 \%$ \\
\hline CGK-HND-CGK & Tetap & $-7,83 \%$ \\
\hline
\end{tabular}

\section{Route Profitability}

Perhitungan route profitability setelah joint venture mencakup parameter antara lain revenue, pengurangan biaya marketing dan sales karena adanya program joint marketing and sales. Untuk itu berdasarkan kenaikan market share di atas maka diharapkan terdapat kenaikan jumlah penumpang sehingga akan meningkatkan pax revenue. Adapun komponen Net Revenue terdiri dari Pax Revenue, Freight, Mail, dan Others. Sedangkan komponen Biaya (Cost) terdiri dari Direct Traffic Cost, Direct Flight Cost, Indirect Cost, Fleet Cost, Station Cost, dan Marketing \& Adm. Cost.

Untuk komponen pendapatan Freight, Mail, dan Others diasumsikan tetap. Dengan asumsi untuk peningkatan komponen biaya rata-rata yakni CAGR Pax berdasarkan data Kemenpar 2017 4,8\% p.a., Growth Rate Traffic Cost 0,3\% p.a., Growth Rate Fuel Price 4\% p.a., Growth Rate Aircraft Maintenance Cost 5\% p.a., dan Growth Rate Lease Cost 5\% p.a. maka dapat diproyeksikan route profitability untuk sektor Jepang yang dilayani PT. XYZ selama 4 tahun mendatang setelah 
penyesuaian nilai terhadap nilai rata-rata tarif yang baru dan capacity share yakni terlihat dalam Tabel 2 hingga Tabel 5.

Tabel 2.

Proyeksi Route Profitability Rute DPS-NRT-DPS Untuk 4 Tahun Ke Depan

\begin{tabular}{lccccc}
\hline $\begin{array}{l}\text { Route } \\
\text { Profitability }\end{array}$ & SEBELUM JV & TAHUN 1 & TAHUN 2 & TAHUN 3 & TAHUN 4 \\
Net Revenue & $\$ 74.789 .788$ & $\$ 75.356 .324$ & $\$ 78.546 .118$ & $\$ 81.889 .022$ & $\$ 85.392 .385$ \\
CM1 & $\$ 32.893 .582$ & $\$ 32.028 .248$ & $\$ 33.729 .629$ & $\$ 35.525 .317$ & $\$ 37.420 .313$ \\
CM2 & $\$ 30.648 .787$ & $\$ 29.671 .214$ & $\$ 31.254 .743$ & $\$ 32.926 .687$ & $\$ 34.691 .751$ \\
CM3 & $\$ 7.060 .348$ & $\$ 4.903 .353$ & $\$ 5.248 .489$ & $\$ 5.620 .121$ & $\$ 6.019 .856$ \\
Total Cost & $\$ 75.906 .111$ & $\$ 75.273 .420$ & $\$ 78.118 .078$ & $\$ 81.089 .351$ & $\$ 84.192 .978$ \\
RR & $\$-1.116 .323$ & $\$ 82.904$ & $\$ 428.040$ & $\$ 799.671$ & $\$ 1.199 .407$ \\
\hline
\end{tabular}

Tabel 3.

Proyeksi Route Profitability Rute CGK-KIX-CGK Untuk 4 Tahun Ke Depan

\begin{tabular}{lccccc}
\hline $\begin{array}{l}\text { Route } \\
\text { Profitability }\end{array}$ & SEBELUM JV & TAHUN 1 & TAHUN 2 & TAHUN 3 & TAHUN 4 \\
\hline Net Revenue & $\$ 21.197 .816$ & $\$ 26.593 .738$ & $\$ 27.749 .407$ & $\$ 28.960 .547$ & $\$ 30.229 .823$ \\
\hline CM1 & $\$ 6.886 .143$ & $\$ 11.788 .071$ & $\$ 12.430 .222$ & $\$ 13.107 .541$ & $\$ 13.821 .878$ \\
\hline CM2 & $\$ 6.163 .265$ & $\$ 11.029 .049$ & $\$ 11.633 .249$ & $\$ 12.270 .719$ & $\$ 12.943 .215$ \\
\hline CM3 & $\$-3.360 .872$ & $\$ 1.028 .706$ & $\$ 1.132 .888$ & $\$ 1.245 .340$ & $\$ 1.366 .567$ \\
\hline Total Cost & $\$ 26.467 .694$ & $\$ 26.900 .761$ & $\$ 27.952 .248$ & $\$ 29.050 .937$ & $\$ 30.198 .985$ \\
\hline RR & $\$-5.269 .878$ & $\$-307.023$ & $\$-202.841$ & $\$-90.389$ & $\$ 30.838$ \\
\hline
\end{tabular}

Tabel 4.

Proyeksi Route Profitability Rute DPS-KIX-DPS Untuk 4 Tahun Ke Depan

\begin{tabular}{lccccc}
\hline $\begin{array}{l}\text { Route } \\
\text { Profitability }\end{array}$ & SEBELUM JV & TAHUN 1 & TAHUN 2 & TAHUN 3 & TAHUN 4 \\
\hline Net Revenue & $\$ 49.824 .068$ & $\$ 55.411 .775$ & $\$ 57.814 .646$ & $\$ 60.332 .855$ & $\$ 62.971 .938$ \\
\hline CM1 & $\$ 16.510 .146$ & $\$ 20.936 .403$ & $\$ 22.131 .880$ & $\$ 23.394 .914$ & $\$ 24.729 .131$ \\
\hline CM2 & $\$ 14.745 .213$ & $\$ 19.083 .224$ & $\$ 20.186 .042$ & $\$ 21.351 .783$ & $\$ 22.583 .844$ \\
\hline CM3 & $\$-1.140 .948$ & $\$ 2.402 .755$ & $\$ 2.671 .549$ & $\$ 2.961 .567$ & $\$ 3.274 .116$ \\
\hline Total Cost & $\$ 55.555 .547$ & $\$ 56.219 .509$ & $\$ 58.353 .586$ & $\$ 60.581 .777$ & $\$ 62.908 .311$ \\
\hline RR & $\$-5.731 .479$ & $\$-807.734$ & $\$-538.940$ & $\$-248.923$ & $\$ 63.627$ \\
\hline
\end{tabular}

Tabel 5.

Proyeksi Route Profitability Rute CGK-HND-CGK Untuk 4 Tahun Ke Depan

\begin{tabular}{|lccccc|}
\hline $\begin{array}{l}\text { Route } \\
\text { Profitability }\end{array}$ & $\begin{array}{c}\text { SEBELUM } \\
\text { JV }\end{array}$ & TAHUN 1 & TAHUN 2 & TAHUN 3 & TAHUN 4 \\
\hline Net Revenue & $\$ 73.957 .352$ & $\$ 72.683 .627$ & $\$ 75.817 .479$ & $\$ 79.101 .757$ & $\$ 82.543 .679$ \\
\hline CM1 & $\$ 32.548 .731$ & $\$ 29.877 .259$ & $\$ 31.558 .230$ & $\$ 33.332 .289$ & $\$ 35.204 .365$ \\
\hline CM2 & $\$ 30.359 .418$ & $\$ 27.578 .480$ & $\$ 29.144 .512$ & $\$ 30.797 .885$ & $\$ 32.543 .241$ \\
\hline CM3 & $\$ 7.421 .484$ & $\$ 3.493 .649$ & $\$ 3.855 .439$ & $\$ 4.244 .359$ & $\$ 4.662 .038$ \\
\hline Total Cost & $\$ 72.546 .349$ & $\$ 73.823 .559$ & $\$ 76.595 .621$ & $\$ 79.490 .979$ & $\$ 82.515 .222$ \\
\hline RR & $\$ 1.411 .003$ & $\$-1.139 .932$ & $\$-778.142$ & $\$-389.222$ & $\$ 28.457$ \\
\hline
\end{tabular}




\section{KESIMPULAN DAN SARAN}

Dari hasil perhitungan route profitability yang telah dilakukan maka potensi joint venture antara PT. XYZ dan JKL Co., Ltd dapat direalisasikan dimana secara umum terjadi peningkatan route profitability yang cukup signifikan pada tahun ke-4 setelah penyesuaian rata-rata tarif baru dan capacity share. Hasil analisis joint venture tersebut dapat direkomendasikan kepada PT. XYZ agar mulai penjajakan kepada JKL Co., Ltd untuk tahapan selanjutnya.

\section{Ucapan Terima Kasih}

Penulis mengucap syukur kepada Tuhan Yang Maha Esa bahwa penulisan analisis joint venture antara PT. XYZ dan JKL Co., Ltd dapat terselesaikan. Selain itu penulis mengucapkan terima kasih kepada Jajaran Dosen dan Dosen Pembimbing di Universitas Tarumanagara Program Studi Magister Manajamen atas ilmu dan bimbingan yang telah diberikan kepada penulis. Tak lupa dukungan keluarga yang telah diberikan kepada penulis sehingga penulisan ini dapat terselesaikan.

\section{REFERENSI}

Association of Asia Pacific Airlines. (2018, 30 January). Asia Pasific Airlines Record Robust Traffic Demand in 2017, 2.

Association of Asia Pacific Airlines. (2018, 19 October). Embracing Future Challenges. Retrieved February 02, 2019 from AAPA Website http://www.aapairlines.org/speeches-presentations/.

Belobaba, P., Odoni, A., \& Barnhart, C. (2009). The Global Airline Industry. United Kingdom : John Wiley \& Sons. Ltd., Publication.

Bilotkach V., Huschelrath, Kai. (2015). Balancing Competition and Cooperation : Evidence From Transatlantic Airline Market, 1.

Chammas M., Pisarkiewicz A. (2014). Airline Competition, 33-34.

Channon, Derek F., Sammut-Bonnici, Tanya. (2014). Joint Ventures. John Wiley \& Sons, Ltd.

David, Fred. R., David, Forest. R. (2017). Strategic Management : A Competitive Advantage Approach, Concepts and Cases, $16^{\text {th }}$ Edition. USA: Pearson Education Limited.

Gillespie W., Richard, Oliver M. (2012). Antitrust Immunity Grants To Joint Venture Agreements : Evidence From International Airline Alliances, 1.

ICAO. (2017). State of Global Air Transport and ICAO Forecast for Effective Planning. Retrieved from ICAO Website https://www.icao.int/Meetings/ICAN2017/Documents/.

ICF SH\&E. (2014). Summary Report on Net Economic Benefit of Joint Ventures. Journal of ICF $S H \& E .4-5$.

JADC. (2018). Worldwide Market Forecast. Retrieved February 02, 2019 from JADC Website http://www.jadc.jp/en/data/forecast/.

Kementrian Pariwisata. (2017). Data Kunjungan Wisatawan Mancanegara Bulan Desember Tahun 2017. Retrieved May 23, 2018 from Kementrian Pariwisata Website http://www.kemenpar.go.id/userfiles/12 \%20Lapbul\%20Des\%202017\%20(Angka\%20Revis i).pdf.

Kotler P., Keller, Kevin L. (2016). Marketing Management, $15^{\text {th }}$ Edition. USA : Pearson Education Limited.

Kuncoro, Mudrajad. (2013). Metode Riset Untuk Bisnis dan Ekonomi, Edisi 4. Jakarta : Erlangga.

L.E.K Consulting. (2017). Reaching New Heights Together in 2017: How Airlines Can Maximize the Value of Joint Ventures. Insight Work, XIX (30), 3-4.

McMullan K. (2011). North Atlantic: The Metal Neutral Market. Retrieved May 22, 2018 from Aviation Strategy Website https://www.aviationstrategy.aero/newsletter/Mar2011/0/North_Atlantic\%3A_the_metal_neutral_market.

Lewis A., Momin Z., Smith P. (2017). Reaching New Heights Together: How Airline Can Maximize the Value of Joint Ventures. Retrieved May 07, 2018 from L.E.K Consulting 
Website https://www.lek.com/insights/ei/reaching-new-heights-together-2017-how-airlinescan-maximize-value-joint-ventures.

Sulianto. (2010). Analisis Bisnis : Pendekatan Praktis. Yogyakarta : ANDI.

Suryana. (2010). Metode Penelitian : Model Praktis Penelitian Kualitatif dan Kuantitatif. Universitas Pendidikan Indonesia. 